\title{
Physiologically based cord clamping improves cardiopulmonary haemodynamics in lambs with a diaphragmatic hernia
}

\author{
Aidan J Kashyap, ${ }_{1}^{1,2}$ Ryan J Hodges, 1,3 Marta Thio, ${ }^{4,5}$ Karyn A Rodgers, 1,2 \\ Ben J Amberg, ${ }^{1,2}$ Erin V McGillick, ${ }^{1,2}$ Stuart B Hooper, ${ }^{2,6}$ Kelly J Crossley, ${ }^{1,2}$ \\ Philip L J DeKoninck ${ }^{6,7}$
}

${ }^{1} T$ The Ritchie Centre, Hudson Institute of Medical Research, Melbourne, Victoria, Australia ${ }^{2}$ Department of Obstetrics and Gynaecology, Monash University, Melbourne, Victoria, Australia

${ }^{3}$ Monash Women's Service, Monash Health, Melbourne, Victoria, Australia

${ }^{4}$ Newborn Research, Neonatal Services, The Royal Women's Hospital, Melbourne, Victoria, Australia

${ }^{5}$ Neonatal Research, Murdoch Children's Research Institute, Melbourne, Victoria, Australia ${ }^{6}$ The Ritchie Centre, The Hudson Institute for Medical Research, Clayton, Victoria, Australia ${ }^{7}$ Department of Obstetrics and Gynaecology, Erasmus MC, Rotterdam, Zuid-Holland, The Netherlands

\section{Correspondence to}

Dr Philip L J DeKoninck, Hudson Institute of Medical Research,

The Ritchie Centre, Clayton, VIC 3168, Australia;

philip.dekoninck@monash.edu

$\mathrm{KJC}$ and PLJDK contributed equally.

Received 23 January 2019 Revised 16 April 2019

Accepted 16 April 2019

Published Online First

23 May 2019

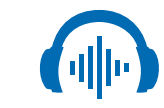

Listen to Podcast adc.bmj.com

\section{Check for updates}

(C) Author(s) (or their employer(s)) 2020. No commercial re-use. See rights and permissions. Published by BMJ.

To cite: Kashyap AJ, Hodges

RJ, Thio M, et al. Arch Dis

Child Fetal Neonatal Ed

2020:105:F1-F8.

\begin{abstract}
Objective Lung hypoplasia associated with congenital diaphragmatic hernia $(\mathrm{CDH})$ results in respiratory insufficiency and pulmonary hypertension after birth. We have investigated whether aerating the lung before removing placental support (physiologically based cord clamping (PBCC)), improves the cardiopulmonary transition in lambs with a CDH.

Methods At $\approx 138$ days of gestational age, 17 lambs with surgically induced left-sided diaphragmatic hernia $(\approx \mathrm{d} 80)$ were delivered via caesarean section. The umbilical cord was clamped either immediately prior to ventilation onset (immediate cord clamping (ICC); $\mathrm{n}=6$ ) or after achieving a target tidal volume of $4 \mathrm{~mL} / \mathrm{kg}$, with a maximum delay of $10 \mathrm{~min}$ (PBCC; $n=11$ ). Lambs were ventilated for $120 \mathrm{~min}$ and physiological changes recorded.
\end{abstract}

Results Pulmonary blood flow (PBF) increased following ventilation onset in both groups, but was 19-fold greater in PBCC compared with ICC lambs at cord clamping ( $19 \pm 6.3$ vs $1.0 \pm 0.5 \mathrm{~mL} / \mathrm{min} / \mathrm{kg}, \mathrm{p}<0.001)$. Cerebral tissue oxygenation was higher in PBCC than ICC lambs during the first 10 min after cord clamping $(59 \% \pm 4 \%$ vs $30 \% \pm 5 \%, p<0.001)$. PBF was threefold higher $(23 \pm 4$ vs $8 \pm 2 \mathrm{~mL} / \mathrm{min} / \mathrm{kg}, \mathrm{p}=0.01)$ and pulmonary vascular resistance (PVR) was threefold lower $(0.6 \pm 0.1$ vs $2.2 \pm 0.6 \mathrm{~mm} \mathrm{Hg} /(\mathrm{mL} / \mathrm{min}), \mathrm{p}<0.001)$ in PBCC lambs compared with ICC lambs at 120 min after ventilation onset.

Conclusions Compared with ICC, PBCC prevented the severe asphyxia immediately after birth and resulted in a higher PBF due to a lower PVR, which persisted for at least 120 min after birth in CDH lambs.

\section{INTRODUCTION}

Congenital diaphragmatic hernia $(\mathrm{CDH})$ is a birth defect that affects 1 in 3000 live births and is responsible for $>1 \%$ of the infant mortality rate in the USA. ${ }^{12}$ The diaphragm fails to close during embryogenesis, which allows abdominal organs to herniate into the chest and disrupt fetal lung development.

The majority of fetuses with isolated $\mathrm{CDH}$ survive until term, because their hypoplastic lungs are not required for gas exchange during fetal life. However, when the umbilical cord is clamped at birth the infant becomes solely dependent on the lungs for gas exchange. The lungs of $\mathrm{CDH}$ infants

\section{What is already known on this topic?}

Umbilical cord clamping stops placental gas exchange and reduces venous return to the heart; lung aeration triggers an increase in pulmonary blood flow (PBF) that restores gas exchange and venous return.

- Infants with congenital diaphragmatic hernia (CDH) have severely hypoplastic lungs and abnormal pulmonary vasculature, which delays the normal increase in PBF after birth, resulting in hypoxia and hypercarbia.

- Physiologically based cord clamping (PBCC) prevents the loss in cardiac output and reduction in oxygenation caused by immediate cord clamping (ICC) in preterm lambs.

\section{What this study adds?}

PBCC in lambs with a diaphragmatic hernia avoided the severe hypoxia associated with ICC and resulted in higher PBFs during the first 2 hours after birth.

- Compared with PBCC, ICC was associated with transient asphyxia, tachycardia and increases in systemic and pulmonary arterial pressures.

- PBCC may improve the cardiopulmonary transition at birth in newborns with a $\mathrm{CDH}$.

are small, with a reduced surface area for gas exchange and reduced pulmonary vascular development, resulting in respiratory insufficiency and pulmonary hypertension soon after birth. ${ }^{3}$

Current guidelines recommend that $\mathrm{CDH}$ infants should be intubated immediately at birth, to avoid inadvertent gaseous distension of the intrathoracic stomach. ${ }^{4}$ In practice, immediate intubation usually translates to immediate umbilical cord clamping at delivery, in order to move the infant to a resuscitation bed for respiratory support. However, we have previously shown that in preterm lambs that require respiratory support, immediate cord clamping (ICC) leads to a transient reduction in cardiac output, marked swings in arterial blood pressures and flows as well as hypoxaemia. ${ }^{56}$

During fetal life, the placental circulation provides the majority of venous return to the left 
heart (preload) via the foramen ovale, as pulmonary blood flow (PBF) is low, due to a high pulmonary vascular resistance (PVR), and unable to sustain left ventricular preload. ${ }^{7}$ Removing the low-resistance placental circulation by clamping the umbilical cord removes this important source of preload, and also increases systemic vascular resistance (afterload). The concurrent increase in afterload and decrease in preload immediately after cord clamping therefore reduces cardiac output. ${ }^{8}$ Cardiac output is only restored when the pulmonary circulation vasodilates (following lung aeration) to accept the entire output of the right ventricle, leading to a large increase in PBF that can sustain left ventricular preload. ${ }^{9}{ }^{10}$ On the other hand, if lung aeration precedes umbilical cord clamping, PBF increases before umbilical venous return is lost and as a result there is no loss in cardiac output following cord clamping. This has been termed physiologically based cord clamping (PBCC). ${ }^{11}$

In normal term infants, lung aeration occurs rapidly and so ICC results in only a limited interruption to cardiac output and gas exchange at birth. In contrast, $\mathrm{CDH}$ infants have stiff, hypoplastic lungs which are likely to take much longer to aerate, as has been demonstrated experimentally. ${ }^{12}$ As lung aeration stimulates the increase in PBF, it is not surprising that the increase in PBF is also delayed in newborn lambs with lung hypoplasia. ${ }^{13}$ As such, ICC in infants with a $\mathrm{CDH}$ may expose them unnecessarily to a prolonged period of hypoxia and reduced cardiac output immediately after birth.

We hypothesise that PBCC in lambs with a diaphragmatic hernia $(\mathrm{DH})$ will avoid a prolonged period of hypoxia and low cardiac output in the newborn period, leading to greatly improved cardiopulmonary haemodynamics and gas exchange immediately after birth. We aimed to provide a detailed description of the effects of PBCC on cardiopulmonary physiology during the fetal to neonatal transition in lambs with a DH.

\section{METHODS}

\section{Ethics statement}

All procedures in animals were performed in accordance with the National Health and Medical Research Council of Australia guidelines for care and use of experimental animals.

\section{General surgical methods}

All surgical procedures were performed under general anaesthesia using intravenous sodium thiopental (Pentothal; Jurox, New Zealand) for induction and inhaled isoflurane $(\approx 2 \%$ in room air; Isoflow, Abbot) for maintenance. Ewes (Merino $\mathrm{X}$ Border-Leicester) were intubated and monitored (ECG, expired $\mathrm{CO}_{2}$, arterial oxygen saturation $\left.\left(\mathrm{SaO}_{2}\right)\right)$ during surgery. ${ }^{14}$

\section{Diaphragmatic hernia creation}

At $\approx 80$ days gestational age $(\mathrm{dGA}$; term $\approx 147 \mathrm{dGA})$, a $\mathrm{DH}$ was surgically created in fetal lambs as previously described. ${ }^{14}$ Following maternal midline laparotomy and hysterotomy, the fetal chest was exteriorised and incised through the left ninth intercostal space. A small incision was made in the fetal diaphragm, through which the stomach and bowels were pulled into the thoracic cavity. Ewes received 3 days of postoperative analgesia (transdermal fentanyl patch, $75 \mu \mathrm{g} /$ hour; Janssen Cilag) and were monitored daily until delivery.

\section{Delivery and ventilation}

Fetal instrumentation

At $\approx 138 \mathrm{dGA}$, ewes and their fetuses were anaesthetised and the lambs instrumented prior to caesarean section delivery as previously described.$^{14}$ Briefly, lambs were partially exteriorised and intubated with a clamped endotracheal tube (size 4.0) prior to instrumentation to prevent lung aeration. Polyvinyl catheters were positioned in the left carotid artery and main pulmonary artery to allow continuous arterial pressure monitoring, and in the left jugular vein to allow neonatal sedation. Ultrasonic flow probes (Transonic Systems, Ithaca, New York, USA) were placed around the right carotid and left pulmonary artery, to continuously record blood flow. A pulse-oximeter (Masimo, Radical 7, California, USA), near-infrared spectroscopy (Casmed Foresight, CAS Medical Systems, Branford, Connecticut, USA) and temperature probe were placed on right forelimb, forehead and rectum, respectively. The stomach was drained via an orogastric tube. After instrumentation, lambs were delivered from the uterus, dried and carefully positioned on the maternal abdomen to avoid occluding the umbilical cord blood flow. The endotracheal tube was unclamped and lung liquid was passively drained.

Each fetus was allocated to either ICC $(n=6)$ or PBCC $(n=11)$ groups. In ICC lambs, the umbilical cord was immediately clamped and cut before ventilation commenced. In PBCC lambs, ventilation commenced first, and umbilical cord clamping was delayed until after a target tidal volume $\left(\mathrm{V}_{\mathrm{T}}\right)$ of $4 \mathrm{~mL} / \mathrm{kg}$ was achieved (maximum delay of $10 \mathrm{~min}$ ).

\section{Ventilation}

In both groups, ventilation commenced with a $30 \mathrm{~s}$ sustained inflation $\left(35 \mathrm{cmH}_{2} \mathrm{O}, 21 \% \mathrm{O}_{2}\right)$ followed by intermittent positive pressure ventilation (iPPV) in volume guarantee mode using a $V_{\mathrm{T}}$ of $4 \mathrm{~mL} / \mathrm{kg}$ (Babylog 8000, Dräger, Lübeck, Germany), peak inspiratory pressure (PIP) limit of $35 \mathrm{cmH}_{2} \mathrm{O}$ and positive end-expiratory pressure of $5 \mathrm{cmH}_{2} \mathrm{O}$. If the target $\mathrm{V}_{\mathrm{T}}$ was not reached after $30 \mathrm{~s}$, a second sustained inflation was performed followed by iPPV for a total of $120 \mathrm{~min}$. After umbilical cord clamping, lambs were moved to a warming bed (CosyCot, Fisher and Paykel, Auckland, New Zealand), and sedated with alfaxalone (10 mg/kg/hour; Alfaxan, Jurox). Respiratory support was titrated to achieve $\mathrm{PaCO}_{2} 60-80 \mathrm{~mm} \mathrm{Hg}, \mathrm{PaO}_{2}>40 \mathrm{~mm} \mathrm{Hg}$ and $\mathrm{SaO}_{2} 85 \%-88 \%$ to allow gentle ventilation. Lambs were euthanised (sodium pentobarbitone intravenous $100 \mathrm{mg} / \mathrm{kg}$ ) after completing the 120 min ventilation protocol or earlier due to ethical end points (ie, treatment-resistant pneumothorax).

\section{Outcome measures}

\section{Physiological data collection}

Pulmonary and carotid arterial blood flows and pressures, cerebral tissue oxygen saturation $\left(\mathrm{SctO}_{2}\right), \mathrm{V}_{\mathrm{T}}$ and airway pressures were continuously recorded using LabChart (ADInstruments, New South Wales, Australia) and analysed offline in 20 s epochs. Arterial blood gas tensions were assessed every $5 \mathrm{~min}$ during the first $30 \mathrm{~min}$ of ventilation and every $10 \mathrm{~min}$ thereafter. PVR, alveolar-arterial difference in oxygen tension and cerebral oxygen delivery were calculated using equations listed in table 1 .

\section{Postmortem examination}

Presence of a diaphragmatic defect and herniation of visceral organs were confirmed during post-mortem examination. Lungs were weighed and expressed as a ratio to the body weight (wet lung-to-body weight ratio).

\section{Statistical analysis}

Data are expressed as means \pm SEM, or medians (IQR) if the data were not normally distributed. The effect of group (ICC vs PBCC), time and interaction between these two effects were 
Table 1 Calculations for derived measures

\begin{tabular}{ll}
\hline Measure & Calculation \\
\hline Pulmonary vascular resistance & (PAP-LAP)/PBF \\
\hline Dynamic lung compliance & $\mathrm{V}_{\mathrm{T}} /$ (PIP-PEEP) \\
\hline Arterial oxygen content $\left(\mathrm{CaO}_{2}\right)^{35}$ & $1.39 \times \mathrm{Hb} \times \mathrm{SaO}_{2} / 100+0.003 \times \mathrm{PaO}_{2}$ \\
\hline Cerebral oxygen delivery & Carotid arterial blood flow $\times \mathrm{CaO}_{2}$ \\
\hline
\end{tabular}

$\mathrm{Hb}$, arterial haemoglobin concentration $(\mathrm{g} / \mathrm{L})$; LAP, left atrial pressure, assumed to equal $9 \mathrm{~mm} \mathrm{Hg}$ based on previous studies ${ }^{36}$; PAP, pulmonary arterial pressure (mm $\mathrm{Hg}$ ); $\mathrm{PaO}_{2}$, partial pressure of arterial oxygen $(\mathrm{mm} \mathrm{Hg}) ; \mathrm{PBF}$, pulmonary blood flow $(\mathrm{mL} / \mathrm{min}) ; \mathrm{PEEP}$, positive end expiratory pressure $\left(\mathrm{cmH}_{2} \mathrm{O}\right)$; PIP, peak inspiratory pressure $\left(\mathrm{cmH}_{2} \mathrm{O}\right) ; \mathrm{SaO}_{2}$, arterial oxygen saturation; $\mathrm{V}_{\mathrm{T}}$, tidal volume $(\mathrm{mL})$.

analysed using two-way repeated measures analysis of variance with post hoc analysis (Holm-Sidak) determining simple effects if an interaction was present (SigmaPlot V.13.0, Systat Software). Statistical significance was accepted when $\mathrm{p}$ value was $<0.05$.

\section{RESULTS}

\section{Baseline fetal characteristics}

Fetal body weight $(4.1 \pm 0.2$ vs $4.5 \pm 0.3 \mathrm{~kg} ; \mathrm{p}=0.21)$, lung-tobody weight ratio $(0.017 \pm 0.002$ vs $0.013 \pm 0.001 ; \mathrm{p}=0.06)$ and percentage of male lambs $(46 \%$ vs $50 \% ; \mathrm{p}=0.99)$ were not significantly different between PBCC and ICC groups. Before delivery, $\mathrm{SaO}_{2}$ was greater in PBCC compared with ICC lambs $(61 \% \pm 3 \%$ vs $48 \% \pm 4 \%$; $\mathrm{p}=0.02)$, but both were within normal range. There was no significant difference in any other arterial blood gas or haemodynamic parameter between groups before delivery (table 2).

It was necessary to discontinue the experimental protocol early in one ICC lamb (at $80 \mathrm{~min}$ ) and two PBCC lambs (at 70 and $100 \mathrm{~min}$ ) due to developing treatment-resistant pneumothoraces.
Arterial blood gas status and cardiopulmonary physiology in the first 10 min after clamping

In the PBCC group, the median period between ventilation onset and cord clamping was $10 \mathrm{~min}$ (range: $3.5-10 \mathrm{~min}$ ). $\mathrm{PaO}_{2}$ and $\mathrm{SaO}_{2}$ values increased following cord clamping in PBCC lambs, whereas values decreased in ICC lambs (figure 1A and B). By 5 min after cord clamping, $\mathrm{PaO}_{2}(45 \pm 12$ vs $11 \pm 1.9 \mathrm{~mm}$ $\mathrm{Hg}, \mathrm{p}=0.006)$ and $\mathrm{SaO}_{2}(70 \% \pm 8.4 \%$ vs $17 \% \pm 6.6 \%, \mathrm{p}<0.001)$ were significantly higher in PBCC compared with ICC lambs. $\mathrm{PaCO}_{2}$ increased and arterial $\mathrm{pH}$ decreased during the $10 \mathrm{~min}$ following cord clamping in both groups (figure $1 \mathrm{C}$ and $\mathrm{D}$ ).

PBF was 19-fold greater in the ventilated PBCC lambs compared with the unventilated ICC lambs at the time of cord clamping $(19.0 \pm 6.3$ vs $1.0 \pm 0.5 \mathrm{~mL} / \mathrm{min} / \mathrm{kg}, \mathrm{p}<0.001)$. PBF increased following cord clamping in both groups, however remained threefold greater in PBCC compared with ICC lambs at $10 \mathrm{~min}$ after cord clamping $(51 \pm 7.8$ vs $18 \pm 4.2 \mathrm{~mL} / \mathrm{min} / \mathrm{kg}$, $\mathrm{p}=0.009$; figure $1 \mathrm{E})$. Pulmonary arterial pressure increased following cord clamping in both groups (figure $1 \mathrm{~F}$ ), and while was not significantly different, tended to be lower in PBCC compared with ICC lambs at 10 min after cord clamping $(64 \pm 2.6$ vs $77 \pm 5.1 \mathrm{~mm} \mathrm{Hg}, \mathrm{p}=0.08$ ).

Carotid blood flow increased during the 10 min following umbilical cord clamping in ICC lambs $(0 \mathrm{~min} 19 \pm 1.7$ vs $10 \mathrm{~min}$ $33 \pm 5.0 \mathrm{~mL} / \mathrm{min} / \mathrm{kg}, \mathrm{p}=0.002$; figure $1 \mathrm{G}$ ), however did not significantly change in PBCC lambs $(0 \mathrm{~min} 18 \pm 2$ vs $10 \mathrm{~min}$ $24 \pm 3.0 \mathrm{~mL} / \mathrm{min} / \mathrm{kg}, \mathrm{p}>0.99$ ). Carotid arterial pressure increased following cord clamping in both groups, but to a lesser degree in PBCC lambs (figure 1H). By 10 min following cord clamping, carotid arterial pressure was $20 \mathrm{~mm} \mathrm{Hg}$ lower in PBCC compared with ICC lambs $(61 \pm 3.8$ vs $80 \pm 5.2 \mathrm{~mm} \mathrm{Hg}, \mathrm{p}=0.02)$. Heart rate increased following cord clamping in ICC lambs, but did not significantly change in PBCC lambs (figure 1I). At 10 min after

Table 2 Ventilation parameters, arterial blood gas status and cardiopulmonary physiology at fetal baseline and during the 120 min neonatal ventilation

\begin{tabular}{|c|c|c|c|c|c|c|c|c|c|}
\hline & \multicolumn{3}{|l|}{ Fetal } & \multicolumn{3}{|l|}{$60 \mathrm{~min}$} & \multicolumn{3}{|l|}{$120 \min$} \\
\hline & ICC & PBCC & $p$ value & ICC & PBCC & $p$ value & ICC & PBCC & $p$ value \\
\hline $\mathrm{DLC}\left(\mathrm{mL} / \mathrm{cmH}_{2} \mathrm{O}\right)$ & - & - & - & $0.6 \pm 0.1$ & $0.5 \pm 0.1$ & 0.23 & $0.7 \pm 0.2$ & $0.6 \pm 0.1$ & 0.32 \\
\hline $\mathrm{FiO}_{2}$ & - & - & - & $0.6 \pm 0.2$ & $0.8 \pm 0.1$ & 0.34 & $0.5 \pm 0.2$ & $0.7 \pm 0.1$ & 0.21 \\
\hline $\mathrm{Hb}(\mathrm{g} / \mathrm{L})$ & $119 \pm 7$ & $134 \pm 4$ & 0.07 & $123 \pm 8$ & $137 \pm 4$ & 0.09 & $131 \pm 10$ & $143 \pm 5$ & 0.10 \\
\hline Hct (\%) & $37 \pm 2$ & $41 \pm 1$ & 0.11 & $38 \pm 2$ & $42 \pm 1$ & 0.09 & $40 \pm 3$ & $44 \pm 2$ & 0.08 \\
\hline $\mathrm{PaO}_{2}(\mathrm{~mm} \mathrm{Hg})$ & $21 \pm 2$ & $25 \pm 1$ & 0.38 & $34 \pm 7$ & $43 \pm 4$ & 0.09 & $34 \pm 7$ & $40 \pm 4$ & 0.36 \\
\hline $\mathrm{SaO}_{2}(\%)$ & $48 \pm 4$ & $61 \pm 3$ & $0.02^{*}$ & $58 \pm 14$ & $76 \pm 7$ & 0.11 & $59 \pm 14$ & $73 \pm 10$ & 0.30 \\
\hline $\mathrm{PaCO}_{2}(\mathrm{~mm} \mathrm{Hg})$ & $64 \pm 2$ & $66 \pm 3$ & 0.95 & $92 \pm 21$ & $95 \pm 15$ & 0.90 & $90 \pm 28$ & $95 \pm 16$ & 0.92 \\
\hline $\mathrm{pH}$ & $7.26 \pm 0.02$ & $7.24 \pm 0.01$ & 0.79 & $7.10 \pm 0.10$ & $7.12 \pm 0.06$ & 0.85 & $7.11 \pm 0.15$ & $7.09 \pm 0.07$ & 0.85 \\
\hline Heart rate & $147 \pm 11$ & $144 \pm 6$ & 0.95 & $184 \pm 11$ & $168 \pm 7$ & 0.23 & $180 \pm 21$ & $171 \pm 8$ & 0.38 \\
\hline PAP $(\mathrm{mm} \mathrm{Hg})$ & $47 \pm 3$ & $52 \pm 4$ & 0.33 & $55 \pm 6$ & $57 \pm 3$ & 0.70 & $55 \pm 5$ & $58 \pm 2$ & 0.33 \\
\hline Mean PBF $(\mathrm{mL} / \mathrm{min} / \mathrm{kg})$ & $1 \pm 0.3$ & $1.4 \pm 1$ & 0.69 & $12 \pm 5$ & $29 \pm 5$ & $0.01^{*}$ & $8 \pm 2$ & $23 \pm 4$ & $0.01^{*}$ \\
\hline PBF/g lung weight & $0.3 \pm 0.1$ & $0.6 \pm 0.3$ & 0.81 & $3.5 \pm 1.5$ & $5.2 \pm 0.6$ & 0.34 & $1.8 \pm 0.5$ & $4.0 \pm 0.4$ & $0.04^{*}$ \\
\hline End-diastolic PBF & $-9 \pm 1$ & $-12 \pm 2$ & 0.45 & $4 \pm 4$ & $12 \pm 3$ & $0.02^{*}$ & $0.6 \pm 1$ & $11 \pm 3$ & $0.02^{*}$ \\
\hline PVR $(\mathrm{mm} \mathrm{Hg}) /(\mathrm{L} / \mathrm{min})$ & $6.1 \pm 0.7$ & $5.2 \pm 0.7$ & 0.25 & $1.7 \pm 0.6$ & $0.5 \pm 0.1$ & $<0.01 *$ & $2.2 \pm 0.6$ & $0.6 \pm 0.1$ & $<0.01$ * \\
\hline PVR $\times g$ lung weight & $123 \pm 24$ & $119 \pm 17$ & 0.89 & $30 \pm 9$ & $11 \pm 2$ & $<0.01^{*}$ & $37 \pm 8$ & $15 \pm 2$ & $<0.01$ * \\
\hline $\mathrm{CAP}(\mathrm{mm} \mathrm{Hg})$ & $46 \pm 2$ & $53 \pm 3$ & 0.24 & $56 \pm 7$ & $60 \pm 3$ & 0.49 & $56 \pm 6$ & $60 \pm 3$ & 0.26 \\
\hline $\mathrm{CBF}(\mathrm{mL} / \mathrm{min} / \mathrm{kg})$ & $17 \pm 2$ & $22 \pm 1$ & 0.16 & $18 \pm 3$ & $20 \pm 4$ & 0.97 & $14 \pm 3$ & $19 \pm 4$ & 0.62 \\
\hline $\mathrm{SctO}_{2}(\%)$ & $43 \pm 6$ & $56 \pm 2$ & 0.32 & $50 \pm 10$ & $60 \pm 5$ & 0.23 & $55 \pm 10$ & $62 \pm 5$ & 0.51 \\
\hline
\end{tabular}

${ }^{*} p<0.05$. Two-way repeated measures analysis of variance (group, time) with post hoc analysis (Holm-Sidak) determining differences between groups at each timepoint. CAP, carotid arterial pressure; ICC, immediate cord clamping; $\mathrm{CBF}$, carotid arterial blood flow; $\mathrm{DLC}$, dynamic lung compliance; FiO ${ }_{2}$ fraction of inspired oxygen; $\mathrm{Hb}$, arterial haemoglobin concentration; $\mathrm{Hct}$, haematocrit; $\mathrm{PaCO}_{2}$, partial pressure of arterial carbon dioxide; $\mathrm{PaO}_{2^{\prime}}$ partial pressure of arterial oxygen; $\mathrm{PAP}$, pulmonary arterial pressure; $\mathrm{PBCC}$, physiologically based cord clamping; $\mathrm{PBF}$, pulmonary arterial blood flow; $\mathrm{PVR}$, pulmonary vascular resistance; $\mathrm{SaO}_{2}$, arterial oxygen saturation; $\mathrm{SctO}_{2}$, cerebral tissue oxygen saturation. 
A

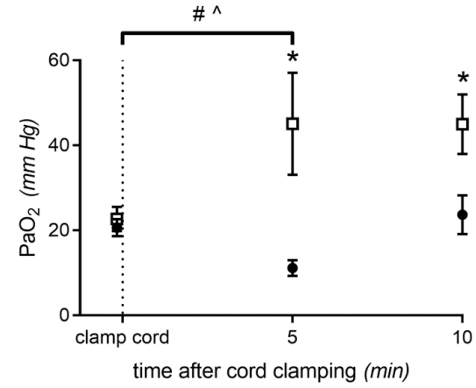

C
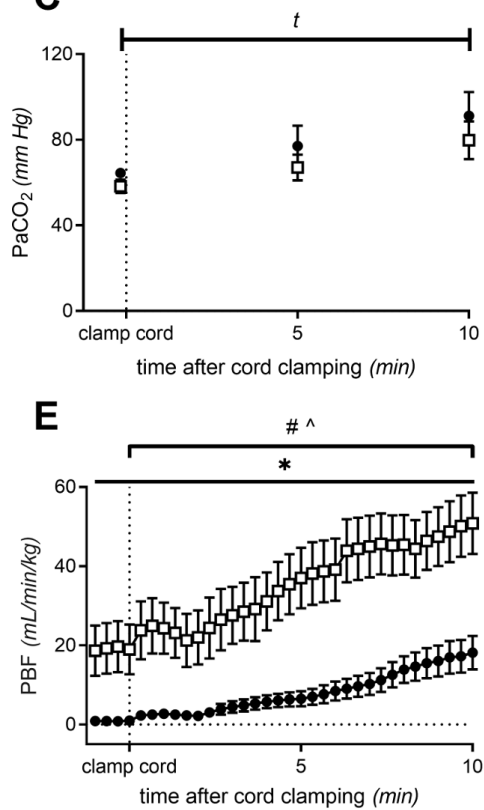

G

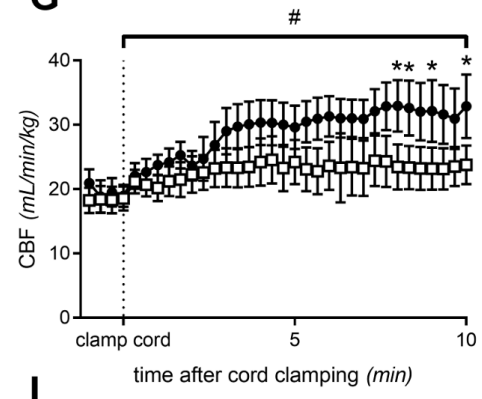

I

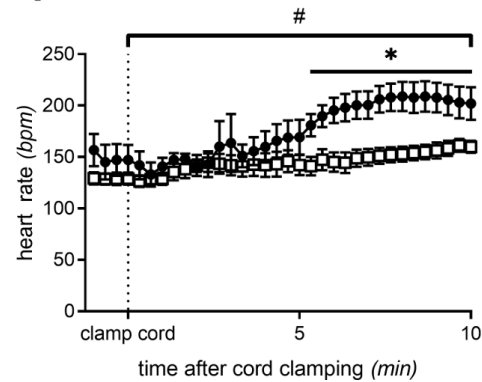

B

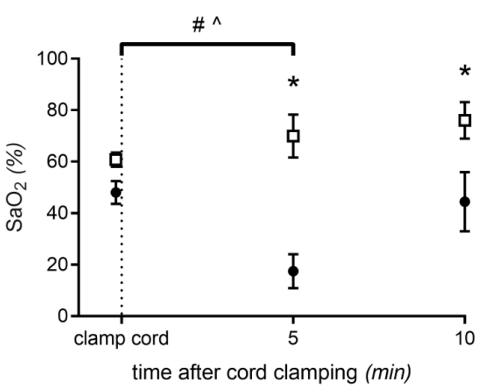

D

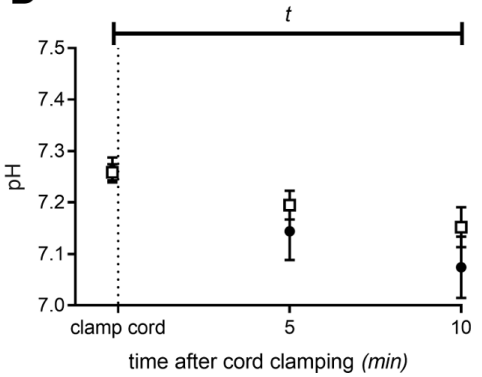

F

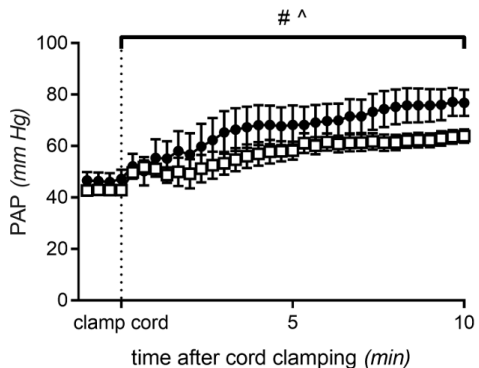

H
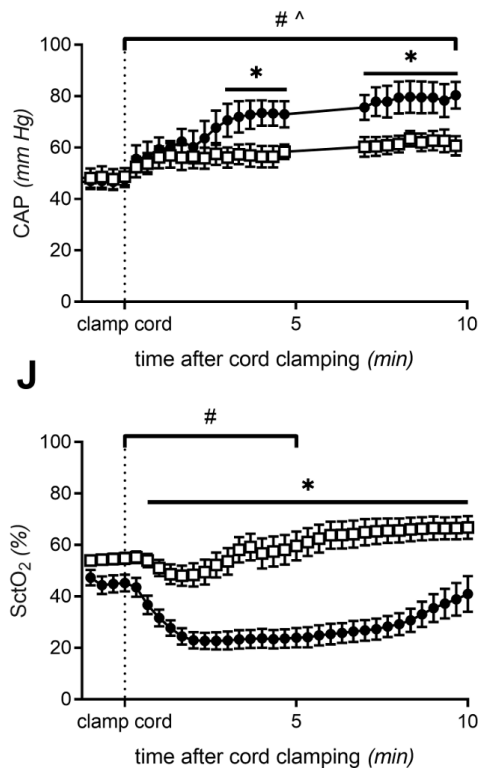

Figure 1 Arterial blood gas status and cardiopulmonary haemodynamics following umbilical cord clamping. (A) Partial pressure of arterial oxygen $\left(\mathrm{PaO}_{2} ; \mathrm{mm} \mathrm{Hg}\right),(\mathrm{B})$ arterial oxygen saturation $\left(\mathrm{SaO}_{2} ; \%\right),(\mathrm{C})$ partial pressure of arterial carbon dioxide $\left(\mathrm{PaCO}_{2} ; \mathrm{mm} \mathrm{Hg}\right),(\mathrm{D})$ arterial pH, (E) pulmonary arterial blood flow (PBF; mL/min/kg), (F) pulmonary arterial blood pressure (PAP; mm Hg), (G) carotid arterial blood flow (CBF; $\mathrm{mL} / \mathrm{min} / \mathrm{kg}),(\mathrm{H})$ carotid arterial blood pressure (CAP; $\mathrm{mm} \mathrm{Hg}$, no data obtained while catheter used to obtain arterial blood gas sample), (I) heart rate (bpm) and (J) cerebral tissue oxygen saturation $\left(\mathrm{SctO}_{2} ; \%\right)$ during the 10 min following umbilical cord clamping in immediate cord clamping (ICC; black circles, $\left.\mathrm{n}=6\right)$ and physiologically based cord clamping (PBCC; white squares, $n=11$ ) groups. Two-way repeated measures analysis of variance (group, time) with HolmSidak's multiple comparisons test. ${ }^{*} p<0.05$ for effect of treatment (ICC vs PBCC) at each timepoint below line. ${ }^{t} p<0.05$ for main effect of time. $\# p<0.05$ for effect of time between the two indicated timepoints in ICC lambs, $\wedge p<0.05$ for effect of time between the two indicated timepoints in PBCC lambs. 

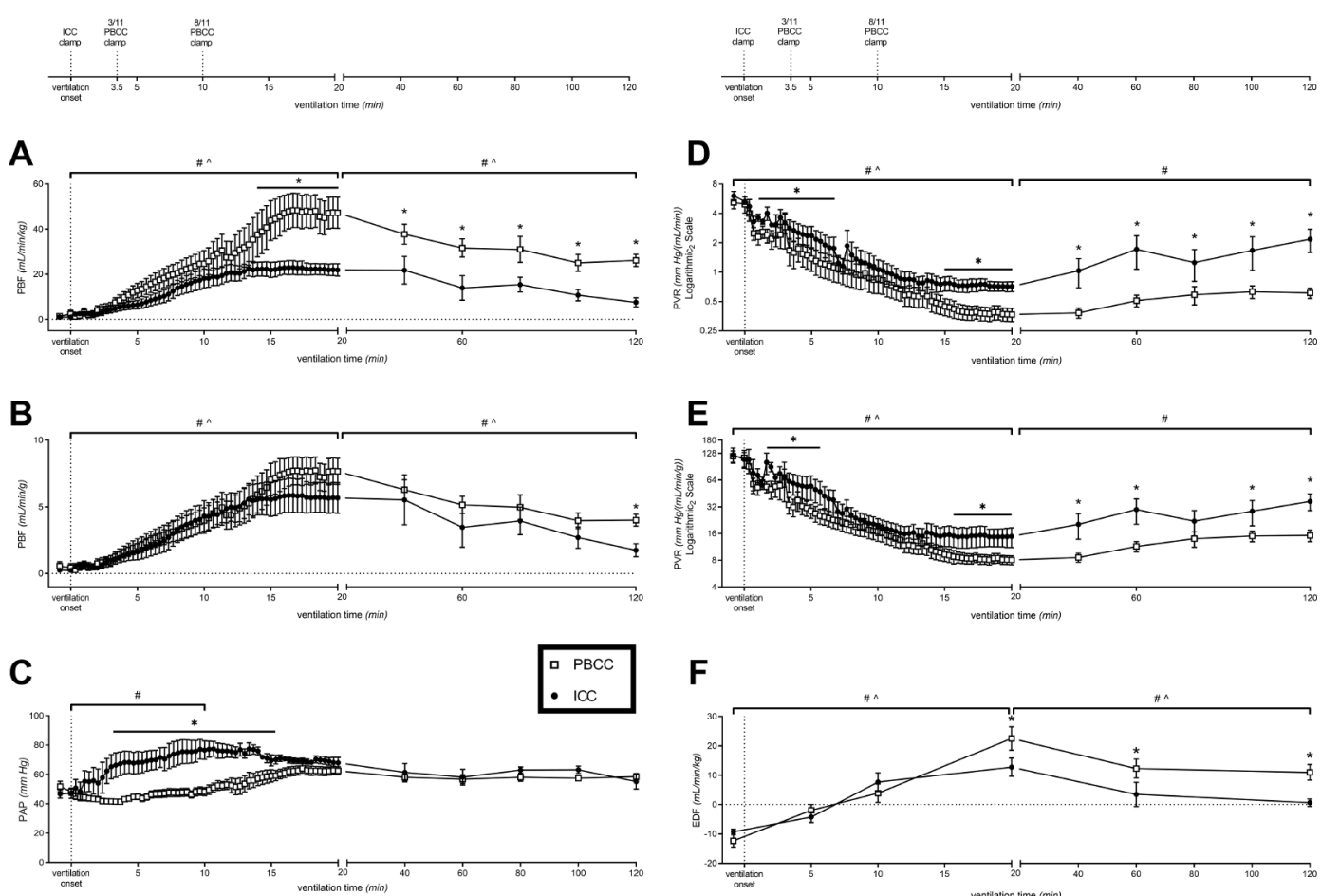

Figure 2 Pulmonary haemodynamics during the 120 min neonatal ventilation. The timing of umbilical cord clamping relative to ventilation onset is shown at the top of the figure, in immediate cord clamping (ICC; cord clamped immediately prior to ventilation onset) and physiologically based cord clamping (PBCC; cord clamped when target tidal volume of $4 \mathrm{~mL} / \mathrm{kg}$ achieved, up to a maximum of 10 min after ventilation onset) groups. (A) Pulmonary arterial blood flow corrected for body weight (PBF; $\mathrm{mL} / \mathrm{min} / \mathrm{kg})$, (B) PBF corrected for left lung weight $(\mathrm{mL} / \mathrm{min} / \mathrm{g})$, (C) pulmonary arterial blood pressure (PAP; $\mathrm{mm} \mathrm{Hg}$ ), (D) pulmonary vascular resistance (PVR; $\mathrm{mm} \mathrm{Hg} /(\mathrm{mL} / \mathrm{min})$ ) presented on a logarithmic (base 2) scale, (E) PVR corrected for left lung weight $(\mathrm{mm} \mathrm{Hg} /(\mathrm{mL} / \mathrm{min} / \mathrm{g})$ ) presented on a logarithmic (base 2) scale and (F) end-diastolic pulmonary blood flow (EDF; $\mathrm{mL} / \mathrm{min} / \mathrm{kg}$ ) during the 120 min following ventilation onset in ICC (black circles, $n=6$ ) and PBCC (white squares, $n=11$ ) groups. Two-way repeated measures analysis of variance (group, time) with Holm-Sidak multiple comparisons test. ${ }^{*} p<0.05$ for effect of treatment (ICC vs PBCC) at each timepoint below line. $\# p<0.05$ for effect of time between the two indicated timepoints in ICC lambs, $\wedge p<0.05$ for effect of time between the two indicated timepoints in PBCC lambs.

cord clamping, heart rate was slower in PBCC compared with ICC lambs ( $160 \pm 6$ vs $202 \pm 16$ bpm, $\mathrm{p}=0.01)$.

Cerebral oxygen delivery was greater in PBCC compared with ICC lambs at $5 \mathrm{~min}$ following cord clamping $(2.6 \pm 0.5$ vs $0.6 \pm 0.2 \mathrm{~mL} / \mathrm{min} / \mathrm{kg}, \mathrm{p}=0.005)$, however by $10 \mathrm{~min}$ there was no significant difference between groups $(3.2 \pm 0.5$ vs $2.5 \pm 0.8 \mathrm{~mL} /$ $\mathrm{min} / \mathrm{kg}, \mathrm{p}=0.25)$. In ICC lambs, $\mathrm{SctO}_{2}$ decreased to a minimum of $23 \%$ at 2 min following cord clamping, whereas in PBCC lambs there was no significant change in $\mathrm{SctO}_{2}$ following cord clamping (figure 1J). During the first $10 \mathrm{~min}$ after cord clamping, mean $\mathrm{SctO}_{2}$ was significantly greater in PBCC compared with ICC lambs $(59 \% \pm 4 \%$ vs $30 \% \pm 5 \%, \mathrm{p}<0.001)$.

\section{Arterial blood gas status and cardiopulmonary physiology throughout the $120 \mathrm{~min}$ neonatal ventilation}

The target $\mathrm{V}_{\mathrm{T}}(4 \mathrm{~mL} / \mathrm{kg})$ was achieved in 6 PBCC lambs $(55 \%$; median $26 \mathrm{~min}$, range 3-100 $\mathrm{min}$ after ventilation onset) and 3 ICC lambs (50\%; median $30 \mathrm{~min}$, range 3-80 min after ventilation onset). Dynamic lung compliance, $\mathrm{FiO}_{2}$ and arterial blood gas parameters were not significantly different between PBCC and ICC lambs after 60 and $120 \mathrm{~min}$ of neonatal ventilation (table 2).

PBF (corrected for body weight) increased in both groups following ventilation onset, however to a greater degree in PBCC lambs (figure 2A). PBF was twofold greater in PBCC lambs compared with ICC lambs by $20 \mathrm{~min}$ after ventilation onset $(47 \pm 7$ vs $22 \pm 3 \mathrm{~mL} / \mathrm{min} / \mathrm{kg}, \mathrm{p}=0.002)$ and remained threefold greater at $120 \mathrm{~min}(23 \pm 4$ vs $8 \pm 2 \mathrm{~mL} / \mathrm{min} / \mathrm{kg}$, $\mathrm{p}=0.01)$.

As PBF was measured in the left pulmonary artery, we also corrected PBF for left lung weight (figure 2B). Despite there being no significant difference in left lung weight between PBCC and ICC lambs $(24 \pm 6$ vs $20 \pm 9 \mathrm{~g}, \mathrm{p}=0.28)$, after correcting for left lung weight, the difference in PBF between PBCC lambs and ICC lambs was no longer significant at $20 \mathrm{~min}(7.7 \pm 1.0 \mathrm{vs}$ $5.7 \pm 1.1 \mathrm{~mL} / \mathrm{min} / \mathrm{g}, \mathrm{p}=0.21$ ), but remained significantly greater in PBCC lambs at $120 \mathrm{~min}(4.0 \pm 0.4$ vs $1.8 \pm 0.5 \mathrm{~mL} / \mathrm{min} / \mathrm{g}$, $\mathrm{p}=0.04)$.

Pulmonary arterial pressure increased immediately after ventilation onset in ICC lambs (figure 2C), and at $10 \mathrm{~min}$ after ventilation onset was significantly lower in PBCC lambs $(48 \pm 3$ vs $77 \pm 6 \mathrm{~mm} \mathrm{Hg}, \mathrm{p}<0.001)$. By $20 \mathrm{~min}$ after ventilation onset, pulmonary arterial pressure was similar between PBCC lambs and ICC lambs $(63 \pm 3$ vs $68 \pm 4, p=0.38)$.

PVR decreased in both groups following ventilation onset (figure 2D), however to a greater degree in PBCC lambs (at $20 \mathrm{~min} 0.4 \pm 0.1$ vs $0.7 \pm 0.1 \mathrm{~mm} \mathrm{Hg} /(\mathrm{mL} / \mathrm{min}), \mathrm{p}=0.02)$. PVR subsequently increased in ICC lambs, yet remained low in PBCC lambs. By $120 \mathrm{~min}$ after ventilation onset, PVR was threefold lower in PBCC lambs compared with ICC lambs $(0.6 \pm 0.1$ vs $2.2 \pm 0.6 \mathrm{~mm} \mathrm{Hg} /(\mathrm{mL} / \mathrm{min}), \mathrm{p}<0.001)$. After correcting for left lung weight, PVR remained significantly lower in PBCC lambs 
compared with ICC lambs at $120 \mathrm{~min}(15 \pm 2$ vs $35 \pm 10 \mathrm{~mm} \mathrm{Hg}$ / $(\mathrm{mL} / \mathrm{min} / \mathrm{g}), \mathrm{p}<0.001$; figure $2 \mathrm{E})$.

End-diastolic PBF, which inversely correlates with PVR, was retrograde (assigned a negative value) in both PBCC and ICC groups before ventilation onset $(-12 \pm 2 \mathrm{vs}-9 \pm 1 \mathrm{~mL} / \mathrm{min} / \mathrm{kg}$, $\mathrm{p}=0.45)$. At $60 \mathrm{~min}$, end-diastolic PBF was positive in both groups but greater in PBCC compared with ICC lambs $(12 \pm 3$ vs $4 \pm 4 \mathrm{~mL} / \mathrm{min} / \mathrm{kg}, \mathrm{p}=0.02$ ). By $120 \mathrm{~min}$, end-diastolic PBF remained positive in $\mathrm{PBCC}$ lambs but approached 0 in ICC lambs ( $11 \pm 3$ vs $0.6 \pm 1 \mathrm{~mL} / \mathrm{min} / \mathrm{kg}, \mathrm{p}=0.02$; figure $2 \mathrm{~F}$ ).

\section{DISCUSSION}

During the transition from fetal to neonatal life, major physiological changes must occur for the infant to survive, which is particularly challenging for infants with underdeveloped lungs. In this study, we demonstrate that, in DH lambs, establishing lung aeration prior to umbilical cord clamping prevents severe transient hypoxia and facilitates a greater increase in PBF during the first $120 \mathrm{~min}$ of neonatal life, compared with ICC. These findings suggest that a physiological approach to umbilical cord clamping may improve the neonatal transition for infants with a CDH.

When umbilical cord clamping occurs before lung aeration, neonates are separated from the fetal oxygen source (placenta) and progressively become more hypoxaemic until adequate pulmonary gas exchange is established. Most infants avoid severe hypoxia at birth, because they rapidly aerate their lungs, which triggers a large increase in PBF. This facilitates a rapid switch to pulmonary gas exchange, and ensures maintenance of cardiac output. ${ }^{10}$ All of the DH lambs had severely hypoplastic lungs that were difficult to ventilate, and as a result the increase in PBF was delayed and remained low for the first few minutes after ventilation onset. Thus, during this time, as ICC lambs had lost the placenta as an oxygen source, they gradually became very hypoxaemic with markedly reduced cerebral oxygen delivery. On the other hand, as placental gas exchange continued while lung aeration was gradually established in PBCC lambs, oxygenation levels gradually increased over the same time period and remained stable after cord clamping (figure 1J). The transient severe cerebral hypoxia we observed in ICC lambs is concerning, given the well-described neuropathological impact of perinatal asphyxia. ${ }^{15} 16$ Neurodevelopmental dysfunction is increasingly being recognised in the long-term follow-up of infants with $\mathrm{CDH}$, and while there are many potential causative factors, the role of transient neonatal hypoxia related to ICC may warrant further study. ${ }^{17}$

The most striking and unexpected finding of this study was the difference in PBF between ICC and PBCC lambs throughout the ventilation period. This difference was statistically significant from 15 to $120 \mathrm{~min}$ after ventilation onset. However, during the first $15 \mathrm{~min}$, ICC lambs required driving pressures (pulmonary arterial pressures) that were $20-25 \mathrm{~mm}$ $\mathrm{Hg}$ greater than PBCC lambs to achieve similar or slightly reduced PBFs. This finding indicates that PBCC had an immediate beneficial effect on PVR that persisted well into the newborn period. In our previous study, in which all DH lambs had PBCC, we found that the increase in PBF per gram of lung tissue at birth was similar to control lambs, suggesting that the overall reduction in PBF was simply due to a reduction in lung size. ${ }^{14}$ As this was not consistent with a previous study in $\mathrm{DH}$ lambs that received ICC, we considered that this unexpectedly high PBF in DH lambs might be due to PBCC, which we have now confirmed.
The mechanisms underlying the higher PVR in ICC DH lambs are unknown, but cannot be due to a reduced cross-sectional area of the pulmonary vascular bed as the reduction in lung sizes were similar. It has recently been shown that lung aeration causes a global reduction in PVR that, at least initially, is independent of oxygen and is thought to be mediated by a neural reflex. ${ }^{18}$ As this reflex can be activated by partial lung aeration, we would expect a similar response (per gram of tissue) in all lambs. However, after ventilation onset, PVR was different in PBCC and ICC lambs, although $\mathrm{PBF}$ was not different due to the higher driving pressure in ICC lambs. Thus, ICC in CDH lambs may activate specific vasoconstrictive responses within the pulmonary vascular bed. Initially, this vasoconstrictive response may be caused by hypoxia, as pulmonary vessels in infants with $\mathrm{CDH}$ are thought to be highly responsive to vasoconstrictive stimuli such as hypoxia. ${ }^{19-21}$ As such, the difference in PVR would be expected to gradually disappear as oxygenation levels between the two groups equalise, which is consistent with the finding of similar PVRs at $10 \mathrm{~min}$ after ventilation onset. However, after $15 \mathrm{~min}$ it diverges again, despite oxygenation levels being similar. This secondary phase of higher PVRs may reflect the gradual onset of persistent pulmonary hypertension of the newborn (PPHN) and while the mechanisms are unknown, it is very interesting that it occurred in most ICC lambs but in no PBCC lambs.

Despite improved pulmonary perfusion, PBCC lambs had persistent hypoxia and hypercapnia, similar to ICC lambs, suggesting that gas exchange remained impaired by the underlying lung hypoplasia. Indeed, in infants with $\mathrm{CDH}$ with relatively mild lung hypoplasia, resuscitation with an intact umbilical cord for $\sim 7 \mathrm{~min}$ increased $\mathrm{pH}$ and reduced $\mathrm{pCO}_{2}$ levels in the first $30 \mathrm{~min}$ after birth. ${ }^{22}$ While survival rates and length of hospital stay were similar, the study only assessed feasibility in infants with relatively mild lung hypoplasia. In more severe cases, a smoother cardiopulmonary transition may avoid reactive vasoconstriction to the severe asphyxia caused by ICC and reduce the incidence and/or severity of PPHN.

The increase in carotid arterial pressure following ICC results from a sudden increase in systemic vascular resistance caused by removal of the low resistance placental circulation. However, if PVR decreases before cord clamping, the pulmonary circulation becomes an alternative low resistance pathway for blood flow due to the onset of left-to-right flow through the ductus arteriosus. ${ }^{58}$ As a result, when cord clamping follows lung aeration (PBCC), the rapid increase in arterial pressure caused by cord clamping is greatly reduced. As PVR remained relatively high in ICC, and to a lesser extent, in PBCC lambs, arterial pressures increased in both groups in response to cord clamping, although to a greater degree in ICC lambs. ICC (but not PBCC) lambs also experienced transient tachycardia and hypertension at approximately 2-3 min following cord clamping. These findings likely result from a sympathetic response to low oxygen tensions immediately following cord clamping that was largely absent in PBCC lambs. ${ }^{23} 24$ PBCC lambs were able to maintain cerebral oxygen delivery without tachycardia or a pressure-driven increase in carotid blood flow.

End-diastolic PBF, which reflects left-to-right shunting through the ductus arteriosus, was present in PBCC lambs, but largely absent in ICC lambs by the end of the $120 \mathrm{~min}$ neonatal ventilation period. The loss of left-to-right shunting and the re-emergence of right-to-left shunting (as occurs prenatally) during diastole, suggests that PVR was progressively increasing back to fetal levels. In contrast, in PBCC 
lambs end-diastolic PBF remained positive, suggesting that the higher PBF in PBCC lambs partially reflects a continuing contribution of flow from the systemic circulation, via the ductus arteriosus, at $120 \mathrm{~min}$.

Although our lambs were delivered via caesarean section in a controlled environment, the feasibility of replicating this approach clinically in the delivery room is slowly being realised. ${ }^{25} 26$ Several studies have now assessed the feasibility of assessing, resuscitating and ventilating infants at the maternal bedside in preterm ${ }^{27}$ and very preterm ${ }^{28} 29$ infants, as well as infants with CDH. ${ }^{22}{ }^{30}$ However, other confounding factors such as labour and oxytocin administration and their potential effects on umbilical blood flow and cardiopulmonary haemodynamics have not been assessed. ${ }^{31}$ On the other hand, it is possible that our findings underestimate the beneficial effects of PBCC in clinical practice, because we were able to commence ventilation within $10 \mathrm{~s}$ of cord clamping in ICC lambs. This is because the lambs had already been intubated (with a clamped endotracheal tube) during fetal instrumentation. Clinically, respiratory support may be delayed for up to $60 \mathrm{~s}$, so the hypoxic period between cord clamping and lung aeration would presumably be much longer than demonstrated in our lamb study. ${ }^{32}$

Our study adds to the growing consensus that a physiological approach to umbilical cord clamping, which includes resuscitation on the cord if required, is preferable to immediate, or even time-based delayed cord clamping. ${ }^{5} 112225-2933$ The majority of our PBCC lambs did not achieve their target $\mathrm{V}_{\mathrm{T}}$, so umbilical cord clamping was delayed until our arbitrary maximum of $10 \mathrm{~min}$. If cord clamping had occurred at $3 \mathrm{~min}$ after ventilation onset, merely to optimise placental transfusion, many of the benefits of PBCC would not have been realised, as both $\mathrm{V}_{\mathrm{T}}$ and PBF remained low (figure 2B). ${ }^{34}$ As our PBCC lambs did not experience transient hypoxia despite not achieving their target $\mathrm{V}_{\mathrm{T}}$, this target may have been an overly conservative target to guide cord clamping. It is possible that similar benefits could have been achieved at an earlier timepoint and so alternative targets, such as exhaled $\mathrm{CO}_{2}$ may prove more useful for guiding cord clamping time. ${ }^{27}$

In conclusion, we found that establishing lung aeration prior to umbilical cord clamping avoids transient, severe hypoxia at birth and enables increased PBF in lambs with a DH for at least the first 120 min after birth. Our findings suggest that a physiological approach to umbilical cord clamping will enable a better transition to newborn life for infants with a $\mathrm{CDH}$.

Correction notice This paper has been amended since it was published Online First. The statement 'KJC and PLJDeK share joint senior authorship' was erroneously omitted during the production process and this has now been reinstated.

Acknowledgements The authors would like to acknowledge the technical assistance of Alison Moxham, Dr llias Nitsos, Valerie Zahra, Dr Sasha Skinner and Dalibor Stanojkovic.

Contributors All authors included in this paper fulfill the criteria of authorship, specifically: PLJD, AJK, RJH, KJC, MT and SBH designed the experiments. AJK, KJC, MT, KAR, BJA, EVM, PLJD and SBH were essential for undertaking the experiments. AJK, PLJD, KJC and SBH were responsible for data analysis. AJK wrote the first draft of the manuscript; PLJD and KJC provided initial critical feedback. All authors contributed by modifying and editing the manuscript and all approved final version.

Funding This research project was funded by grants from the Royal Australian and New Zealand College of Obstetricians and Gynaecologists (RANZCOG) Foundation, Cabrini Foundation, CDH Australia and the Victorian Government's Operational Infrastructure Support Program.

Disclaimer The funders were not involved in the study design; in the collection, analysis and interpretation of the data; in the writing of the report or in the decision to submit the paper for publication.

Competing interests None declared.
Patient consent for publication Not required.

Ethics approval All procedures in animals were approved by the animal ethics committee at Monash University.

Provenance and peer review Not commissioned; externally peer reviewed.

\section{REFERENCES}

1 Langham MR, Kays DW, Ledbetter DJ, et al. Congenital diaphragmatic hernia. Epidemiology and outcome. Clin Perinatol 1996;23:671-88.

2 Lally KP. Congenital diaphragmatic hernia - the past 25 (or so) years. J Pediatr Surg 2016;51:695-8.

3 Keller RL. Antenatal and postnatal lung and vascular anatomic and functional studies in congenital diaphragmatic hernia: implications for clinical management. Am J Med Genet C Semin Med Genet 2007;145C:184-200.

4 Snoek KG, Reiss IK, Greenough A, et al. Standardized postnatal management of infants with congenital diaphragmatic hernia in Europe: The CDH EURO Consortium Consensus - 2015 Update. Neonatology 2016;110:66-74.

5 Bhatt $\mathrm{S}$, Alison BJ, Wallace EM, et al. Delaying cord clamping until ventilation onset improves cardiovascular function at birth in preterm lambs. J Physiol 2013;591:2113-26.

6 Polglase GR, Dawson JA, Kluckow M, et al. Ventilation onset prior to umbilical cord clamping (physiological-based cord clamping) improves systemic and cerebral oxygenation in preterm lambs. PLoS One 2015;10:e0117504

7 Rudolph AM. Fetal and neonatal pulmonary circulation. Annu Rev Physiol 1979;41:383-95.

8 Crossley KJ, Allison BJ, Polglase GR, et al. Dynamic changes in the direction of blood flow through the ductus arteriosus at birth. J Physio/ 2009;587:4695-704.

9 Hooper SB, Te Pas AB, Lang J, et al. Cardiovascular transition at birth: a physiological sequence. Pediatr Res 2015:77:608-14.

10 Lang JA, Pearson JT, Binder-Heschl C, et al. Increase in pulmonary blood flow at birth: role of oxygen and lung aeration. J Physio/ 2016;594:1389-98.

11 Hooper SB, Polglase GR, te Pas AB. A physiological approach to the timing of umbilical cord clamping at birth. Arch Dis Child Fetal Neonatal Ed 2015;100:F35 5-F360.

12 Flemmer AW, Thio M, Wallace MJ, et al. Lung hypoplasia in newborn rabbits with a diaphragmatic hernia affects pulmonary ventilation but not perfusion. Pediatr Res 2017;82:536-43.

13 McGillick EV, Davies IM, Hooper SB, et al. JAPPL-00760-2018 Effect of lung hypoplasia on the cardiorespiratory transition in newborn lambs. J App/ Physiol 2019.

14 Kashyap AJ, Crossley KJ, DeKoninck PLJ, et al. Neonatal cardiopulmonary transition in an ovine model of congenital diaphragmatic hernia. Arch Dis Child Fetal Neonatal Ed 2019;104:F617-23.

15 Brown JK, Purvis RJ, Forfar JO, et al. Neurological aspects of perinatal asphyxia. Dev Med Child Neurol 1974;16:567-80

16 Johnston MV, Trescher WH, Ishida A, et al. Neurobiology of hypoxic-ischemic injury in the developing brain. Pediatr Res 2001;49:735-41.

17 Danzer E, Kim SS. Neurodevelopmental outcome in congenital diaphragmatic hernia: Evaluation, predictors and outcome. World J Clin Pediatr 2014;3:30-6.

18 Lang JA, Pearson JT, Binder-Heschl C, et al. Vagal denervation inhibits the increase in pulmonary blood flow during partial lung aeration at birth. J Physiol 2017:595:1593-606.

19 Tarry D, Powell M. Hypoxic pulmonary vasoconstriction. BJA Educ 2017;17:208-13.

20 Kinsella JP, Ivy DD, Abman SH. Pulmonary vasodilator therapy in congenital diaphragmatic hernia: acute, late, and chronic pulmonary hypertension. Semin Perinatol 2005;29:123-8.

21 de Lagausie P, de Buys-Roessingh A, Ferkdadji L, et al. Endothelin receptor expression in human lungs of newborns with congenital diaphragmatic hernia. J Pathol 2005:205:112-8.

22 Lefebvre C, Rakza T, Weslinck N, et al. Feasibility and safety of intact cord resuscitation in newborn infants with congenital diaphragmatic hernia (CDH). Resuscitation 2017; 120:20-5.

23 Carroll JL, Kim I. Carotid chemoreceptor "resetting" revisited. Respir Physiol Neurobio 2013;185:30-43.

24 Sobotka KS, Morley C, Ong T, et al. Circulatory responses to asphyxia differ if the asphyxia occurs in utero or ex utero in near-term lambs. PLoS One 2014;9:e112264.

$25 \mathrm{Knol}$ R, Brouwer E, Vernooij ASN, et al. Clinical aspects of incorporating cord clamping into stabilisation of preterm infants. Arch Dis Child Fetal Neonatal Ed 2018;103:F49 3-F497.

26 Niermeyer S, Velaphi S. Promoting physiologic transition at birth: re-examining resuscitation and the timing of cord clamping. Semin Fetal Neonatal Med 2013:18:385-92.

27 Blank DA, Badurdeen S, Omar F Kamlin C, et al. Baby-directed umbilical cord clamping: A feasibility study. Resuscitation 2018:131:1-7.

28 Brouwer E, Knol R, Vernooij ASN, et al. Physiological-based cord clamping in preterm infants using a new purpose-built resuscitation table: a feasibility study. Arch Dis Child Fetal Neonatal Ed 2019;104:F396-402. 
29 Duley L, Dorling J, Pushpa-Rajah A, et al. Randomised trial of cord clamping and initial stabilisation at very preterm birth. Arch Dis Child Fetal Neonatal Ed 2018;103:F6-F14.

30 ClinicalTrials.gov [Internet]. NCT03314233, Delayed cord clamping for intubation and gentle ventilation in infants with congenital diaphragmatic hernia. Bethesda (MD): National Library of Medicine, 2017.

31 Bhatt S, Polglase GR, Wallace EM, et al. Ventilation before umbilical cord clamping improves the physiological transition at birth. Front Pediatr 2014;2:113.

32 Perlman JM, Wyllie J, Kattwinkel J, et al. Part 7: Neonatal Resuscitation: 2015 International Consensus on Cardiopulmonary Resuscitation and Emergency Cardiovascular Care Science With Treatment Recommendations (Reprint). Pediatrics 2015;136(Suppl 2):S120-S166.
33 Polglase GR, Blank DA, Barton SK, et al. Physiologically based cord clamping stabilises cardiac output and reduces cerebrovascular injury in asphyxiated near-term lambs. Arch Dis Child Fetal Neonatal Ed 2018;103:F530-F538.

34 Katheria $\mathrm{AC}$, Lakshminrusimha S, Rabe $\mathrm{H}$, et al. Placental transfusion: a review. J Perinatol 2017;37:105-11.

35 Lumb AB. Nunn's applied respiratory physiology: Elsevier Health Sciences, 2016.

36 Polglase GR, Morley CJ, Crossley KJ, et al. Positive end-expiratory pressure differentially alters pulmonary hemodynamics and oxygenation in ventilated, very premature lambs. J App/ Physio/ 2005;99:1453-61. 